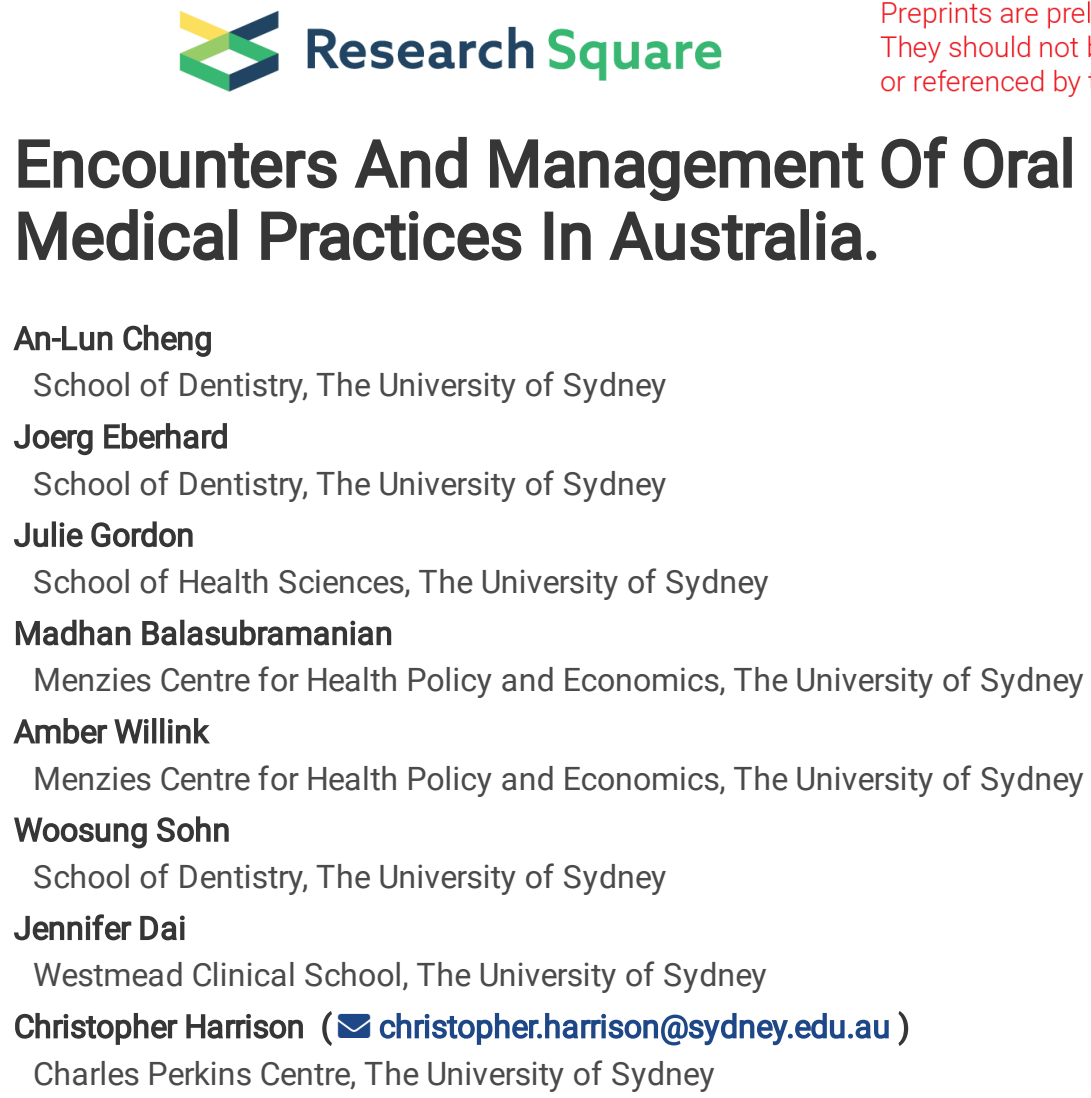

\title{
Encounters And Management Of Oral Conditions At General Medical Practices In Australia.
}

\section{Research Article}

Keywords: oral health, primary care, general practitioner, health services, health policy

Posted Date: February 21st, 2022

DOI: https://doi.org/10.21203/rs.3.rs-1348298/v1

License: (c) (i) This work is licensed under a Creative Commons Attribution 4.0 International License. Read Full License 


\section{Abstract}

Background: Poor oral health has been widely recognised as an ongoing public health issue. Patients with oral conditions may visit either a general practitioner (GP) or an oral health practitioner for management. The aims of this study are to report (i) the GP management rate of oral health conditions by patient and GP demographics, (ii) what specific oral conditions were managed, and (iii) how GPs managed oral conditions.

Methods: Data from the Bettering the Evaluation and Care of Health study (2006 to 2016 inclusive) were analysed. Descriptive statistics with $95 \%$ confidence intervals around point estimates were used to summarise data. Multivariate logistic regression was performed to determine the independent effect of patient and GP characteristics.

Results: A total of $972,100 \mathrm{GP}$ encounters were included in the dataset, with oral condition-related encounters managed at a rate of 1.19 oral conditions per $100 \mathrm{GP}$ encounters. Patients who were aged 54 years or younger, resided in a socioeconomically disadvantaged area, came from a non-English speaking background or Indigenous background were more likely to have oral conditions managed by GPs. The most commonly reported oral conditions were dental and oral mucosa-related. Over $60 \%$ of oral conditions were managed by GPs through prescribed medications.

Conclusions: This study provided an overview of management of oral conditions by GPs in Australia. Patients from certain vulnerable demographic groups were more likely to attend a GP for management of oral conditions. Common oral conditions and management approaches were identified. The findings of this study contribute to public health and health policy discussions around optimising primary care provision in oral health.

\section{Background}

Oral health is a widely neglected global public health issue. ${ }^{1}$ The Global Burden of Disease Study 2017 estimated 3.5 billion cases of oral conditions globally, with majority of these conditions being untreated caries and severe periodontitis. ${ }^{1}$ These conditions are frequently accompanied by pain and impaired function, leading to interference with daily activities and influencing overall health. ${ }^{2}$ Poor oral health has been shown to have negative effects on other health conditions including cardiovascular disease and diabetes. ${ }^{3,4}$ Undoubtedly, the recognition and effective management of oral conditions are imperative to alleviate this ongoing public health challenge.

Barriers that prevent people with oral conditions from appropriate treatment include limited public funded dental care, out of pocket expenses, poor accessibility, and dental fear or anxiety. $5,6 \mathrm{In}$ most countries, there is an unequal distribution of oral health services between urban and rural areas and a strong relationship between poor oral health and socioeconomic status (SES) ${ }^{7,8} \mathrm{~A}$ lack of accessible public oral health services may also prohibit people from low socioeconomic backgrounds in acquiring proper services to manage their oral conditions. ${ }^{5}$ These barriers to accessing oral health services may potentially redirect individuals to consider treatment from alternative medical services, such as general practitioners (GP) and hospital emergency departments (ED).

Medical services may bring improved accessibility for provision of treatment of oral conditions. ${ }^{9,10}$ A 2010 study among adults in the state of Maryland, US demonstrated that $14.3 \%$ visited a medical doctor for dental problems. ${ }^{11}$ Secondary data analyses from Canada and the United Kingdom (UK) revealed that an average of 0.6 to 1.3 visits per 100 patients per year to a physician or GP were for oral condition-related diagnoses. ${ }^{12,13}$ Due to the emerging number of studies worldwide on patients seeking medical services for oral conditions, there has been an increase in recognition of the potential role of a primary care medical practitioners in relieving oral health disparities. ${ }^{11,14,15}$

Contemporarily, oral health in the context of integrated healthcare has been an emerging topic. Primary care pathways for improving oral health in vulnerable population groups were highlighted in recent Australian studies. ${ }^{16-19}$ Furthermore, collaborative healthcare models have been integrated in Australian community oral health programs, involving multidisciplinary health professionals such as doctors, nurses, and dieticians. ${ }^{20,21}$ Despite the emphasis on the importance of integrated oral healthcare by recent studies, there is a lack of literature on the types of oral conditions managed in primary care settings and how these conditions are managed. Moreover, little is known about the demographic characteristics of patients who receive oral health care in primary care settings, which may facilitate recognition of traits in patients who are more likely to present oral conditions to GPs and traits in GPs who are more likely to manage oral conditions. Such information may allow for development of public health initiatives to improve the oral health care provided by GPs to vulnerable population groups. 
The aims of this study are to describe (i) the demographics of patients who had oral conditions managed by a GP from 2006 to 2016 ; (ii) the demographics of GPs who managed these oral conditions; (iii) the type and rate of oral conditions managed by GPs and (iv) how GPs managed these oral conditions.

\section{Methods}

\section{Data Collection and Source}

Data for the study were sourced from the last ten years (2006-16) of the Bettering the Evaluation and Care of Health (BEACH) study, a continuous cross-sectional study of general practice activity conducted from 1998-2016. The BEACH methods have been described in detail elsewhere. ${ }^{22}$ In brief, the BEACH data captured general practice clinical activity from an ever-changing, random sample of approximately 1,000 Australian GPs each year. The BEACH study had a single stage cluster design with each GP participant recording details of 100 consecutive encounters with patients' informed consent.

Data items and management

Encounter details included patient characteristics, up to three reasons for encounter, up to four problems managed, new or follow-up problem status and method of management. Management actions were recorded as medications (inclusive of prescribed, supplied and advised for over-the-counter purchase), therapeutic procedures, clinical treatments, referrals, pathology and imaging tests ordered. Each management action was explicitly linked to the specific problem or diagnosis managed. New problems were defined as the first presentation of a problem or previously-resolved recurrent problem.

Patients' reasons for encounter, problems or diagnoses managed and non-pharmacological management actions were coded according to ICPC-2 PLUS, an interface terminology classified to the International Classification of Primary Care-Version 2 (ICPC-2) ${ }^{23}$ The Anatomic Therapeutic Chemical (ATC) classification was used to classify medications among recorded management details. ${ }^{24}$ The Index of Relative Socio-Economic Advantage and Disadvantage (IRSAD) was used to record patient relative socioeconomic status based on patient residential post code. ${ }^{25}$ Scores $1-5$ were classified as socio-economically advantaged while scores $6-10$ were classified as socio-economically disadvantaged. The geographic location of the GP practice was classified using the Australian Statistical Geography Standard (ASGS). ${ }^{26}$ For this study, the groups Outer regional, Remote and Very remote were grouped into one group called Outer regional/Remote. Patient Indigenous status was determined by whether they self-identified as Aboriginal and/or Torres Strait Islander. Patient language background was determined by whether the patient spoke a language other than English at home.

Other patient characteristics recorded include sex, age and Health Care Concession Card (HCC) status. Reported GP characteristics include sex, age, practice size by number of GPs at practice and by full-time equivalent GPs at practice, and country of graduation. Oral problems or diagnoses (by ICPC-2 PLUS code) were grouped into main groups of conditions including dental, oral mucosal (oral soft tissues including gum, tongue and palate), temporomandibular joint, oral glands, trauma, neuralgia, and dental related conditions. These conditions were then classified into sub-groups to provide greater detail (Appendix A).

\section{Data analysis}

Each GP (sampling unit) has a cluster of 100 patient encounters (unit of inference) around them. To adjust for this cluster, robust $95 \%$ confidence intervals (Cls) were calculated using survey procedures in SAS 9.4. Statistical significance of difference between point estimates was determined by non-overlapping $95 \% \mathrm{Cls}$. This method is more conservative than the usual $5 \%$ level, reducing the risk of type I errors, while increasing the risk of type II errors. ${ }^{27}$ To determine the independent effect of patient and GP characteristics, a multivariate logistic regression was performed using the survey logistic procedure in SAS 9.4 which also took clustering into account.

Ethics

The BEACH program has ethics approval from the Human Research Ethics Committee of the University of Sydney (reference no. : 2012/130) and the Australian Institute of Health and Welfare (AlHW) Ethics Committee for the relevant years of collaboration (2006-11).

\section{Results}

Patient Characteristics 
A total of 9,721 GPs recorded 972,100 patient encounters, over the 10-year period of the BEACH study. During the observation period, 11,546 oral conditions were managed at a rate of 1.19 oral conditions per 100 encounters (Table 1). An annual national estimate of $1,684,000$ encounters when extrapolated to the 143 million MBS GP items of service claimed in $2015-16 .^{22}$ People aged 70 years or older had a significantly lower oral condition management rate than in those aged 54 years and younger. Significantly higher GP management rates of oral conditions were reported in patients living in socioeconomically disadvantaged areas, HCC holders, patients from non-English speaking backgrounds, and Aboriginal and Torres Strait Islander patients (Table 1). 
Table 1

GP and patient specific management rates of oral conditions, 2006 to 2016.

\begin{tabular}{|c|c|c|c|c|c|}
\hline & $\begin{array}{l}N \\
(n= \\
972,100)\end{array}$ & $\begin{array}{l}\text { Number of oral } \\
\text { conditions } \\
\text { managed }\end{array}$ & $\begin{array}{l}\text { Distribution }(\%) \text { of oral } \\
\text { conditions managed } \\
(95 \% \mathrm{Cl})\end{array}$ & $\begin{array}{l}\text { Characteristic specific oral } \\
\text { conditions managed per } 100 \\
\text { encounters }(95 \% \mathrm{Cl})\end{array}$ & $\begin{array}{l}\begin{array}{l}\text { Odds ratios } \\
\text { (multiple logistic } \\
\text { regression) }\end{array} \\
(95 \% \mathrm{Cls})\end{array}$ \\
\hline \multicolumn{6}{|l|}{$\begin{array}{l}\text { Patient } \\
\text { Characteristics }\end{array}$} \\
\hline Gender & 8,522 & 114 & $40.1 \%(39.1-41.1)$ & $1.17(1.14-1.21)$ & $p=0.1759$ \\
\hline Missing & 391,152 & 4,585 & $59.9 \%(58.9-60.9)$ & $1.20(1.17-1.23)$ & Reference group \\
\hline Male & 572,426 & 6,847 & & & 1.031 \\
\hline \multicolumn{6}{|l|}{ Female } \\
\hline Age & 19,222 & 194 & $12.1 \%(11.5-12.8)$ & $1.24(1.17-1.31)$ & $p<0.0001$ \\
\hline Missing & 110,864 & 1378 & $9.0 \%(8.4-9.5)$ & $1.25(1.17-1.33)$ & $1.45(1.29-1.64)$ \\
\hline $0-14$ years & 81,201 & 1,017 & $16.7 \%(15.9-17.4)$ & $1.28(1.21-1.34)$ & $1.45(1.28-1.64)$ \\
\hline $15-24$ years & 148,287 & 1,891 & $21.4 \%(20.6-22.1)$ & $1.30(1.24-1.35)$ & $1.54(1.37-1.73)$ \\
\hline $25-39$ years & 186,787 & 2,426 & $20.8 \%(20.0-21.6)$ & $1.15(1.10-1.19)$ & $1.53(1.36-1.72)$ \\
\hline $40-54$ years & 206,331 & 2,365 & $15.7 \%(15.0-16.4)$ & $1.04(0.99-1.10)$ & $1.27(1.14-1.42)$ \\
\hline $55-69$ years & 170,665 & 1,782 & $4.3 \%(3.9-4.8)$ & $1.01(0.91-1.11)$ & $1.00(0.90-1.12)$ \\
\hline $70-84$ years & 48,743 & 493 & & & Reference Group \\
\hline \multicolumn{6}{|l|}{$85+$ years } \\
\hline \multirow{2}{*}{$\begin{array}{l}\text { Socioeconomic } \\
\text { status }\end{array}$} & 22,692 & 266 & $57.2 \%(55.9-58.4)$ & $1.12(1.09-1.15)$ & $p=0.0251$ \\
\hline & 573,803 & 6,449 & $42.8 \%(41.6-44.1)$ & $1.29(1.25-1.33)$ & Reference Group \\
\hline \multirow{2}{*}{$\begin{array}{l}\text { Missing } \\
\text { Advantaged } \\
\text { Disadvantaged }\end{array}$} & 375,605 & 4,831 & & & $1.06(1.01-1.11)$ \\
\hline & & & & & \\
\hline \multirow{2}{*}{$\begin{array}{l}\text { Concession Card } \\
\text { Status }\end{array}$} & 80,058 & 823 & $51.5 \%(50.4-52.5)$ & $1.39(1.35-1.43)$ & $p<0.0001$ \\
\hline & 396,992 & 5,518 & $48.5 \%(47.5-49.6)$ & $1.05(1.02-1.08)$ & $1.49(1.42-1.56)$ \\
\hline \multirow{2}{*}{$\begin{array}{l}\text { Missing } \\
\text { Cardholder } \\
\text { Non-cardholder }\end{array}$} & 495,050 & 5,205 & & & Reference Group \\
\hline & & & & & \\
\hline \multirow{2}{*}{$\begin{array}{l}\text { Language } \\
\text { background }\end{array}$} & 95,865 & 976 & $11.3 \%(10.5-12.2)$ & $1.60(1.50-1.71)$ & $p<0.0001$ \\
\hline & 74,672 & 1,198 & $88.7 \%(87.8-89.5)$ & $1.17(1.14-1.20)$ & $1.31(1.22-1.41)$ \\
\hline $\begin{array}{l}\text { Missing } \\
\text { Non-English } \\
\text { speaking }\end{array}$ & 801,563 & 9,372 & & & Reference Group \\
\hline \multicolumn{6}{|l|}{ English speaking } \\
\hline \multirow{2}{*}{$\begin{array}{l}\text { Indigenous } \\
\text { status }\end{array}$} & 95,622 & 978 & $3.5 \%(3.0-4.0)$ & $2.49(2.22-2.77)$ & $p<0.0001$ \\
\hline & 14,791 & 369 & $96.5 \%(96.0-97.0)$ & $1.18(1.16-1.21)$ & $1.87(1.65-2.12)$ \\
\hline $\begin{array}{l}\text { Missing } \\
\text { Indigenous }\end{array}$ & 861,687 & 10,199 & & & Reference Group \\
\hline Non-Indigen & & & & & \\
\hline
\end{tabular}

Cl: confidence interval. 


\begin{tabular}{|c|c|c|c|c|c|}
\hline & $\begin{array}{l}N \\
(n= \\
972,100)\end{array}$ & $\begin{array}{l}\text { Number of oral } \\
\text { conditions } \\
\text { managed }\end{array}$ & $\begin{array}{l}\text { Distribution (\%) of oral } \\
\text { conditions managed } \\
(95 \% \mathrm{Cl})\end{array}$ & $\begin{array}{l}\text { Characteristic specific oral } \\
\text { conditions managed per } 100 \\
\text { encounters }(95 \% \mathrm{Cl})\end{array}$ & $\begin{array}{l}\text { Odds ratios } \\
\text { (multiple logistic } \\
\text { regression) } \\
\text { (95\% Cls) }\end{array}$ \\
\hline $\begin{array}{l}\text { GP } \\
\text { Characteristics }\end{array}$ & & & & & \\
\hline $\begin{array}{l}\text { Gender } \\
\text { Missing }\end{array}$ & 0 & 0 & & & $p=0.7678$ \\
\hline Male & 583,200 & 6,984 & $60.5 \%(59.1-61.9)$ & $1.20(1.17-1.23)$ & Reference group \\
\hline Female & 388,900 & 4,562 & $39.5 \%(38.1-40.9)$ & $1.17(1.13-1.21)$ & $0.99(0.95-1.04)$ \\
\hline $\begin{array}{l}\text { Age } \\
\text { Missing }\end{array}$ & 6,400 & 83 & & & $p=0.4575$ \\
\hline$<45$ years & 250,500 & 2,951 & $25.7 \%(24.5-27.0)$ & $1.18(1.13-1.23)$ & Reference group \\
\hline $45-59$ years & 473,400 & 5,544 & $48.4 \%(46.9-49.8)$ & $1.17(1.14-1.21)$ & $0.99(0.95-1.04)$ \\
\hline $60+$ years & 241,800 & 2,968 & $25.9 \%(24.6-27.2)$ & $1.23(1.18-1.28)$ & $1.03(0.96-1.10)$ \\
\hline $\begin{array}{l}\text { Practice location } \\
\text { Missing }\end{array}$ & 1,400 & 18 & & & $p=0.0024$ \\
\hline Major Cities & 687,500 & 8,253 & $71.8 \%(70.5-73.1)$ & $1.20(1.17-1.23)$ & $1.13(1.04-1.22)$ \\
\hline Inner Regional & 187,800 & 2,134 & $18.3 \%(17.3-19.4)$ & $1.14(1.08-1.19)$ & $1.04(0.95-1.13)$ \\
\hline $\begin{array}{l}\text { Outer } \\
\text { Regional/Remote }\end{array}$ & 95,400 & 1,141 & $9.9 \%(9.0-10.7)$ & $1.20(1.12-1.28)$ & Reference group \\
\hline $\begin{array}{l}\text { Practice size } \\
\text { Missing }\end{array}$ & 18,900 & 234 & & & $p=0.0019$ \\
\hline Solo GP & 103,600 & 1,427 & $12.6 \%(11.6-13.6)$ & $1.38(1.29-1.47)$ & Reference group \\
\hline 2-4 GPs & 287,100 & 3,427 & $30.3 \%(29.0-31.6)$ & $1.19(1.15-1.24)$ & $0.88(0.82-0.96)$ \\
\hline 5-9 GPs & 365,500 & 4,109 & $36.3 \%(34.9-37.7)$ & $1.12(1.09-1.16)$ & $0.85(0.78-0.92)$ \\
\hline $10-14$ GPs & 136,500 & 1,601 & $14.2 \%(13.1-15.2)$ & $1.17(1.11-1.24)$ & $0.88(0.80-0.96)$ \\
\hline $15+\mathrm{GPs}$ & 60,500 & 748 & $6.6 \%(5.9-7.3)$ & $1.24(1.14-1.33)$ & $0.87(0.78-0.97)$ \\
\hline $\begin{array}{l}\text { Country of } \\
\text { graduation } \\
\text { Missing }\end{array}$ & 2,700 & 31 & & & $p=0.7983$ \\
\hline $\begin{array}{l}\text { Overseas } \\
\text { graduate }\end{array}$ & 297,300 & 3,659 & $31.8 \%(30.4-33.1)$ & $1.23(1.19-1.28)$ & $1.01(0.96-1.06)$ \\
\hline $\begin{array}{l}\text { Australian } \\
\text { graduate }\end{array}$ & 672,100 & 7,856 & $68.2 \%(66.9-69.6)$ & $1.17(1.14-1.20)$ & Reference Group \\
\hline Time & & & & & $p=0.4451$ \\
\hline Year & & & & & $1.00(1.00-1.01)$ \\
\hline
\end{tabular}

The multiple logistic regression model showed that patients aged 25-39 years were the most likely to have oral conditions managed at GP encounters, approximately $54 \%$ more likely compared to patients aged 70 years or above (Table 1 ). The modelling also revealed a higher likelihood of having oral conditions managed by GPs for patients who lived in socioeconomically disadvantaged areas $(6 \%$ more 
likely), Concession card holders (49\% more likely), patients from non-English speaking backgrounds (31\% more likely), and Aboriginal and Torres Strait Islander patients (87\% more likely) compared to their reference groups.

GP characteristics

Management rates of oral conditions by GP characteristics are depicted in Table 1. GPs working in solo GP practices (1.38 per 100 encounters) or in a practice with 15 or more GPs (1.24 per 100 encounters) were significantly more likely to manage an oral health condition at an encounter than those working in practices with 2-14 GPs (1.12 to 1.19 per 100 encounters). The multiple logistic regression model identified practice location and practice size as independent predictors of the number of oral conditions managed by GPs per 100 encounters. An oral condition was $13 \%$ more likely to be managed at an encounter in a major city compared to outer regional/remote areas. A solo GP was 12-15\% more likely to manage an oral condition at encounter than those working with other GPs.

Oral condition related encounter

Among the types of oral conditions, dental and oral mucosa (soft tissues including gums, tongue and palate) related problems had the highest management rates of 426.8 and 419.2 conditions per 100,000 encounters respectively. Management rates of temporomandibular joint related problems and periodontal condition (gum disease) were respectively managed at a rate of 101.0 and 91.2 problems per 100,000 encounters respectively. Other oral conditions including oral gland problems, neuralgia, trauma, and other dental problems (such as teething and problems related to dental prostheses) were managed at low rates of less than 50 problems managed per 100,000 encounters (Fig. 1). Among the oral conditions specifically reported in the present study, dental infection or disease, oral ulceration, oral fungal infection, and dental pain or symptoms were commonly recorded by GPs.

Management actions used for oral condition by GPs

Frequencies and proportions of oral conditions managed with specific management approaches are outlined in Table 2. About $62.2 \%$ of all oral conditions were managed by GPs with one or more medications, which included antibiotics (30.2\%), analgesics (14.4\%), stomatological preparations including topical antifungal and steroid creams $(10.0 \%)$, antimycotics (3.9\%), anti-inflammatory and antirheumatics (4.2\%) and antiepileptics (1.7\%). The next most commonly reported management action used to manage oral conditions were referrals $(21.4 \%)$ (mostly to dentists $(14.7 \%)$ ) followed by and counselling, advice or education (14.9\%). Investigations, such as pathology $(5.5 \%)$ and imaging $(5.3 \%)$ were infrequently used while procedural/physical treatments were rarely used $(2.3 \%)$. 
Table 2

Management actions used for oral conditions by GPs 2006-16.

\begin{tabular}{|c|c|c|}
\hline Management action & $\begin{array}{l}\text { Number of oral conditions treated } \\
\text { with management action } \\
(\mathrm{N}=11,546)\end{array}$ & $\begin{array}{l}\text { Proportion }(\%) \text { of oral conditions managed with at least } \\
\text { one management action }(95 \% \mathrm{Cl})^{\mathrm{a}}\end{array}$ \\
\hline Medication & 7,225 & $62.6 \%(61.6-63.6)$ \\
\hline Antibiotics & 3,490 & $30.2 \%(29.3-31.2)$ \\
\hline Amoxicillin & 1,707 & $14.8 \%(14.1-15.5)$ \\
\hline Amoxicillin/Beta & 800 & $6.9 \%(6.4-7.4)$ \\
\hline Metronidazole oral/systemic & 429 & $3.7 \%(3.3-4.1)$ \\
\hline Cephalexin & 380 & $3.3 \%(2.9-3.6)$ \\
\hline Analgesics & 1,662 & $14.4 \%(13.7-15.1)$ \\
\hline Opioids & 1,017 & $8.8 \%(8.2-9.4)$ \\
\hline Codeine/paracetamol & 807 & $7.0 \%(6.5-7.5)$ \\
\hline Oxycodone & 105 & $0.9 \%(0.7-1.1)$ \\
\hline Tramadol & 95 & $0.8 \%(0.7-1.0)$ \\
\hline Non-opioid analgesics & 669 & $5.8 \%(5.3-6.2)$ \\
\hline Paracetamol & 440 & $3.8 \%(3.4-4.2)$ \\
\hline Stomatological preparations & 1,160 & $10.0 \%(9.5-10.6)$ \\
\hline Nystatin oral topical & 544 & $4.7 \%(4.3-5.1)$ \\
\hline Triamcinolone oropharyngeal & 281 & $2.4 \%(2.1-2.7)$ \\
\hline Antimycotics for systemic use & 449 & $3.9 \%(3.5-4.3)$ \\
\hline Amphotericin oropharyngeal & 419 & $3.6 \%(3.3-4.0)$ \\
\hline $\begin{array}{l}\text { Anti-inflammatory and } \\
\text { antirheumatic }\end{array}$ & 480 & $4.2 \%(3.8-4.5)$ \\
\hline Ibuprofen & 301 & $2.6 \%(2.3-2.9)$ \\
\hline Antiepileptics & 199 & $1.7 \%(1.5-2.0)$ \\
\hline Carbamazepine & 102 & $0.9 \%(0.7-1.1)$ \\
\hline Referral & 2,466 & $21.4 \%(20.5-22.2)$ \\
\hline Dentist & 1,699 & $14.7 \%(14.0-15.5)$ \\
\hline Surgeon & 160 & $1.4 \%(1.2-1.6)$ \\
\hline $\begin{array}{l}\text { Ears, nose and throat } \\
\text { specialist }\end{array}$ & 141 & $1.2 \%(1.0-1.4)$ \\
\hline Gastroenterologist & 98 & $0.8 \%(0.7-1.0)$ \\
\hline Counselling/Advice/Education & 1,724 & $14.9 \%(14.2-15.7)$ \\
\hline Imaging & 615 & $5.3 \%(4.9-5.7)$ \\
\hline X-ray & 267 & $2.3 \%(2.0-2.6)$ \\
\hline Ultrasound & 177 & $1.5 \%(1.3-1.8)$ \\
\hline
\end{tabular}

a Percentages of management actions under each sub-category may not add up to percentages of their respective categories as GPs may provide more than one management action per encounter. 


\begin{tabular}{|lll|}
\hline Management action & $\begin{array}{l}\text { Number of oral conditions treated } \\
\text { with management action } \\
(\mathbf{N}=\mathbf{1 1}, \mathbf{5 4 6})\end{array}$ & $\begin{array}{l}\text { Proportion (\%) of oral conditions managed with at least } \\
\text { one management action }(\mathbf{9 5 \%} \mathrm{Cl})^{\mathbf{a}}\end{array}$ \\
\hline Barium - swallow/meal & 116 & $1.0 \%(0.8-1.2)$ \\
\hline CT & 76 & $0.7 \%(0.5-0.8)$ \\
\hline Pathology & 630 & $\mathbf{5 . 5 \% ( 5 . 0 - 5 . 9 )}$ \\
\hline Full blood count & 294 & $2.5 \%(2.2-2.8)$ \\
\hline Other microbiology & 144 & $1.2 \%(1.0-1.5)$ \\
\hline Ferritin & 102 & $0.9 \%(0.7-1.1)$ \\
\hline Vitamin B12 & 96 & $0.8 \%(0.7-1.0)$ \\
\hline Procedural treatments & $\mathbf{3 3 6}$ & $\mathbf{2 . 9 \%}(\mathbf{2 . 6 - 3 . 2 )}$ \\
\hline $\begin{array}{l}\text { a Percentages of management actions under each sub-category may not add up to percentages of their respective categories as GPs } \\
\text { may provide more than one management action per encounter. }\end{array}$ \\
\hline
\end{tabular}

\section{Discussion}

General Statement

This study showed a high prevalence of oral condition-related encounters at GP practices in Australia with an annual national estimation of 1,684,000 encounters. Among the reported oral conditions, dental and mucosal-related conditions were the two most commonly managed types. Medications, referrals to dentists and surgeons, and counselling, advice or education were common management actions for oral conditions. To our knowledge, this nationwide study is the first to provide detailed information about patient and GP characteristics, encounters and management of oral conditions by GPs in Australia.

\section{Encounters}

At Australian GP practices, oral conditions were managed at a rate of 1.19 per 100 encounters. This result of this study may not be directly compared to past UK and Canadian studies' results on management of oral conditions in GP and physician practice setting due to differences in study design, however the potential disparities in these rates may be attributed to differences in healthcare systems. ${ }^{28}$ While the UK, Canada and Australia provide universal medical healthcare for individuals, there are differences in how dental services are funded. Dental services in the UK are funded by government and provided by the National Health Service, ${ }^{29}$ while dental services in Canada and Australia incur solely private contributions and are only funded by the Government for eligible individuals (low-income earners and pensioners). ${ }^{2,30,31}$ In Australia, out-of-pocket costs have been identified as a major barrier to accessing oral health care in a high proportion of people aged 15 years and over. ${ }^{2}$ Cost is therefore likely a reason for people to consult GPs for their oral conditions.

\section{Patient demographics}

Deterioration in general health as individuals age may lead to adverse effects on oral health and the ability to attend health services. ${ }^{32}$ The present study found that individuals aged 70 years or more attended GPs for the management of oral conditions at significantly lower rates than those aged 54 years or younger. This finding aligns with results of National Study of Adult Oral Health 2017-2018 which reported a decreasing trend in adults of older age groups reporting delays or avoidance of dental care due to costs. ${ }^{33}$ Older Australians also present more frequently to GPs for general health conditions, ${ }^{34}$ which in turns decreases the relative management rate of oral conditions despite possibly having a similar rate of oral conditions management to other age groups.

Global studies consistently show that individuals with disadvantaged SES are more likely to have poor oral health and associated pain compared to those with advantaged SES. ${ }^{35-38}$ The cumulation of low SES, costs for dental services and poor oral health may explain the higher GP management of oral conditions among patients from areas of disadvantaged SES. To reduce public health SES-related inequity, the Australian Government introduced healthcare subsidies in the form of the Health Care Concession Card (HCC), providing free public oral health services to those eligible. ${ }^{33}$ However, $\mathrm{HCC}$ holders reportedly have poorer oral health than non-HCC holders attributable 
to financial barriers preventing access to private services and long waiting lists preventing access to public services. ${ }^{33}$ As GP and ED services are more readily accessible, vulnerable Australians may instead seek management through these services instead.

There has been a rise in population of migrants from non-English speaking countries, whom personal oral hygiene practices and health literacy may be different to those raised in Australia. ${ }^{40}$ Lower oral health literacy and poorer oral health were reported in migrant populations in Australia, Canada, and the US as a result of linguistic and cultural differences. ${ }^{40,41}$ Poorer oral health, lack of oral health literacy, cultural and linguistic diversities are possible justification for the higher likelihood of seeking non-oral health professionals such as GPs for management of oral conditions.

Similarly, Australian studies consistently reveal poorer oral health among Indigenous people compared to non-Indigenous peers, in spite of the Australian Government's effort in improving Indigenous oral health care. ${ }^{42-44}$ This is likely to be correlated to social determinants of health among these communities reflected by the inequalities in education, jobs, and experiences of discrimination. ${ }^{45,46}$

GP demographics

This study identified significantly higher likelihood of oral condition-related encounters at GP practices located in major cities and solo practices. This observation is unexpected as the dental practitioner to GP ratio per population size has been historically lower in regional or remote areas compared to major cities. ${ }^{47,48}$ Furthermore, financial barriers may be more prevalent among residents of rural areas compared to major cities, attributed to a higher proportion of people from low socio-economic backgrounds in rural areas. ${ }^{49}$ The correlation between GP demographics and likelihood of managing oral conditions remains obscure and may need clarification in future studies.

Oral conditions

Among the oral conditions managed by GPs, dental and oral mucosal related problems were the most prevalently reported in this study. These findings align well with a study of medical practitioners in the province of Ontario, Canada. This study identified diseases of the teeth and supporting structure, diseases of hard tissues, and diseases of oral soft tissues excluding lesions specific for gingiva and tongue as the most common oral conditions seen by a medical practitioner. ${ }^{12}$

\section{Management}

For the management of oral conditions, GPs prescribed antibiotics and analgesics, referred to a dentists or dental surgeon, and provided counselling, advice, or education. In general, most dental conditions require procedural treatments outside of GP's scope of practice that involves extensive diagnostic procedures. ${ }^{50,51}$ In contrast, the prescription of antibiotics in the dental practice has been defined as lowvalue care, because antibiotics are rarely helpful with relieving the source of infection, symptoms or present harm to the population by antibiotic resistance, and introduces economical and pharmaceutical wastage. ${ }^{52}$ The correct management of oral mucosal conditions, on the other hand, require accurate diagnostic skills and techniques acquired by education not included in medical education curriculum. ${ }^{53-55}$

Despite the best intent in addressing patients' oral conditions, the lack of confidence in managing oral conditions is commonly reported among GPs in Australia. ${ }^{56}$ As oral conditions are commonly encountered in GP practices, integrating oral health education in medical curricula and continuous professional development of medical practitioners in diagnosis and management of common oral diseases may improve GP's confidence and accuracy in managing oral conditions while facilitating timely referral to appropriate oral health practitioners.

Implications

This study showed that a proportion of patients are consulting GPs for management of oral conditions in Australia. Although the reason for seeing a GP instead of a dentist for managing oral conditions was not explored in this study, past studies have identified high cost and low accessibility as barriers for Australians in accessing oral health care. ${ }^{5}$ These barriers may explain the higher likelihood of having oral conditions managed by GPs in vulnerable population groups such as HCC holders and people from a non-English speaking background, low SES background or Indigenous background. As there is a lack of public funding in oral health care in Australia, approximately 4 in 10 Australians aged 15 years and over avoided or delayed visiting a dentist due to cost. ${ }^{57}$ Furthermore, it should also 
be noted that more than four out of five dentists work in a private care setting ${ }^{57}$ Australians who cannot afford or access oral health care may end up seeing a GP for management.

GPs may be exposed to patients who may require urgent management of oral conditions. During these appointments, GPs commonly prescribed medications, provided advice and referred patients to other health professionals such as dentists. As GPs may be involved in oral health care in primary care settings, improving oral health training of GP may in turn improve GPs engagement in the management of oral conditions. Furthermore, a standardised referral pathway from GP to dental practitioner may be developed to improve patients' rate of dental attendance, which potentially leads to reduction of oral diseases and improvement of self-rated health. ${ }^{58}$

Limitations

Although the BEACH dataset provides a large sample size with linkage of GP's management approach to the oral conditions, this study did not establish the linkage between the management approach and the conditions. While also possible, this study did not report the difference in GP management rates between new and old or recurrent oral conditions. The management of specific oral conditions (new and old) will be examined in subsequent studies. The results of this study are limited to Australian GPs and may not be generalised to other countries. Furthermore, this study has assumed the accuracy of the diagnosis made by the GPs as it is not possible to validate the accuracy.

Future Research

This study provides a snapshot of current state of oral condition-related encounters in the Australian general practice setting. Findings of this study pave the way for opportunities to improve value and quality of oral health care, and alleviate inequity in accessing oral healthcare. Future studies may be conducted using the BEACH dataset in the investigation of specific oral conditions and management approaches by GPs. Public health initiatives can be developed in educating GPs and other primary care providers (such as nurses and allied health professionals) to recognise, manage, and facilitate timely referral of oral conditions to reduce low-value care and improve overall public health outcomes. Furthermore, policymakers may recognise disadvantaged populations and redirect oral healthcare access to individuals who are susceptible to poor oral health.

\section{Conclusion}

This study provides a preliminary overview of management of oral condition-related problems by GPs based on patient and GP characteristics, specific oral conditions managed, and management approaches used by GPs. Patients with certain vulnerable demographics were more likely to attend a GP for management of oral conditions. Common oral conditions and management approaches among these encounters were identified. The study suggests that there is a potentially significant role for primary care practitioners such as GPs in providing oral health care. The findings of this study contribute to public health and health policy discussions around optimising primary care provision in oral health.

\section{Abbreviations}

AlHW: Australian Institute of Health and Welfare

ASGS: Australian Statistical Geography Standard

ATC: Anatomic Therapeutic Chemical classification

$\mathrm{BEACH}$ : Bettering the Evaluation and Care of Health study

Cl: confidence intervals

ED: emergency department

GP: general practitioner

HCC: Health Care Concession Card

ICPC-2: International Classification of Primary Care-Version 2

Page 11/15 
IRSAD: Index of Relative Socio-Economic Advantage and Disadvantage

SES: socioeconomic status

UK: United Kingdom

\section{Declarations}

Ethics approval and consent to participate

All methods were carried out in accordance with relevant guidelines and regulations. The BEACH program has ethics approval from the Human Research Ethics Committee of the University of Sydney (reference no.: 2012/130) and the Australian Institute of Health and Welfare (AlHW) Ethics Committee for the relevant years of collaboration (2006-11). Informed consent was obtained from all subjects.

Consent for publication

Not applicable.

Availability of data and materials

The raw BEACH data are not publicly available due to the sensitivity around health data. Researchers with ethically appropriate research questions can request access to the data via the University of Sydney. They can contact Dr Christopher Harrison at christopher.harrison@sydnety.edu.au for further information about access.

Competing interests

The authors declare that they have no competing interests.

Funding

The BEACH study was financially supported by the following organisations between 2006 and 2016: AstraZeneca Pty. Ltd. (Australia); Australian Government Department of Health; Novartis Pharmaceuticals Australia Pty. Ltd.; bioCSL (Australia) Pty. Ltd.; Sanofi-Aventis Australia Pty. Ltd.; Australian Government Department of Veterans' Affairs; AbbVie Pty. Ltd.; Merck, Sharpe and Dohme (Australia) Pty. Ltd.; Pfizer Australia; National Prescribing Service; GlaxoSmithKline Australia Pty. Ltd.; Bayer Australia Ltd.; Janssen-Cilag Pty. Ltd.; Abbott Australasia Pty. Ltd.; Wyeth Australia Pty. Ltd.; Roche Products Pty. Ltd. and Aventis Pharma Pty. Ltd.

C.H. is currently a NHMRC Early Career Fellow (ID: 1163058).

Authors' contributions

C.H., J.E., W.S., A.W., M.B., A.C. and J.G. made substantial contribution to the study concept and design. C.H. and J.G. contributed to acquisition and analysis of data. A.C., J.E., C.H. contributed to interpretation of data. A.C., J.E., C.H., and J.D. contributed to the manuscript preparation. C.H., J.E., W.S., A.W., M.B., J.G., A.C., and J.D. reviewed and approved the final manuscript.

Acknowledgements

We would like to thank the BEACH team for collecting the data and for all the GPs who participated in data collection.

\section{References}

1. Bernabe E, Marcenes W, Hernandez CR, Bailey J, Abreu LG, Alipour V, Amini S, Arabloo J, Arefi Z, Arora A. Global, regional, and national levels and trends in burden of oral conditions from 1990 to 2017: a systematic analysis for the global burden of disease 2017 study. J Dent Res. 2020 Apr;99(4):362-73.

2. COAG (Council of Australian Governments) Health Council. Healthy Mouths, Healthy Lives: Australia's National Oral Health Plan 2015-2024. Adelaide (AU): South Australian Dental Service; 2015.

3. D'Aiuto F, Gkranias N, Bhowruth D, Khan T, Orlandi M, Suvan J, Masi S, Tsakos G, Hurel S, Hingorani AD, Donos N. Systemic effects of periodontitis treatment in patients with type 2 diabetes: a 12 month, single-centre, investigator-masked, randomised trial. Lancet

Page $12 / 15$ 
Diabetes Endocrinol. 2018 Dec 1;6(12):954 - 65.

4. Zhou QB, Xia WH, Ren J, Yu BB, Tong XZ, Chen YB, Chen S, Feng L, Dai J, Tao J, Yang JY. Effect of intensive periodontal therapy on blood pressure and endothelial microparticles in patients with prehypertension and periodontitis: a randomized controlled trial. $\mathrm{J}$ Periodontol. 2017 Aug;88(8):711-22.

5. Marshall R, Spencer A. Accessing oral health care in Australia. Med J Aust. 2006 Jul 17;185(2):59-60.

6. Cohen LA, Bonito AJ, Akin DR, Manski RJ, Macek MD, Edwards RR, Cornelius LJ. Toothache pain: a comparison of visits to physicians, emergency departments and dentists. J Am Dent Assoc. 2008 Sep 1;139(9):1205-16.

7. Godwin D, Hoang H, Crocombe L, Bell E. Dental practitioner rural work movements: a systematic review. Rural Remote Health. 2014 Jul 29;14(3), 431.

8. Peres MA, Macpherson LM, Weyant RJ, Daly B, Venturelli R, Mathur MR, Listl S, Celeste RK, Guarnizo-Herreño CC, Kearns C, Benzian H. Oral diseases: a global public health challenge. Lancet. 2019 Jul 20;394(10194):249-60.

9. Department of Health. Report of the National Advisory Council on Dental Health [final report] [Internet]. Canberra (AU): Department of Health; 2012 Feb 23. Available from: https://www1.health.gov.au/internet/main/publishing.nsf/Content/C10065B9A 8B6790FCA257BF0001BDB29/\$File/Final\%20Report\%20of\%20the\%20NACDH\%20\%2026\%20February\%202012\%20(PUBLICATION).pdf

10. Australian Institute of Health and Welfare. Potentially preventable hospitalisations in Australia by age groups and small geographic areas, 2017-18 [Internet]. Canberra: Australian Institute of Health and Welfare, 2019 [cited 2021 Dec 11]. Available from: https://www.aihw.gov.au/reports/primary-health-care/potentially-preventable-hospitalisations

11. Cohen LA, Bonito AJ, Eicheldinger C, Manski RJ, Macek MD, Edwards RR, Khanna N. Comparison of patient visits to emergency departments, physician offices, and dental offices for dental problems and injuries. J Public Health Dent. 2011 Jan;71(1):13-22.

12. LaPlante NC, Singhal S, Maund J, Quiñonez C. Visits to physicians for oral health-related complaints in Ontario, Canada. Can J Public Health. 2015 Mar;106(3):e127-31.

13. Cope AL, Chestnutt IG, Wood F, Francis NA. Dental consultations in UK general practice and antibiotic prescribing rates: a retrospective cohort study. Br J Gen Pract. 2016 May 1;66(646):e329-36.

14. Phillips KE, Hummel J. Oral health in primary care: a framework for action. JDR Clin Trans Res. 2016 Apr;1(1):6-9.

15. Balasubramanian M, Keuskamp D, Amarasena N, Brennan D. Predictors for oral and general health outcomes and quality of life among older people attending general practice clinics in South Australia. Gerodontology. 2021 Jan 21;38(4):395-403.

16. Barnett T, Hoang H, Stuart J, Crocombe L. Non-dental primary care providers' views on challenges in providing oral health services and strategies to improve oral health in Australian rural and remote communities: a qualitative study. BMJ Open. 2015 Oct 1;5(10):e009341.

17. Keuskamp D, Amarasena N, Balasubramanian M, Brennan DS. General health, wellbeing and oral health of patients older than 75 years attending health assessments. Aust J Prim Health. 2018 May 8;24(2):177-82.

18. Poudel P, Griffiths R, Wong VW, Arora A, Flack JR, Khoo CL, George A. Perceptions and practices of general practitioners on providing oral health care to people with diabetes-a qualitative study. BMC Fam Pract. 2020 Dec;21(1):1-1.

19. Shrivastava R, Couturier Y, Girard F, Papineau L, Emami E. Two-eyed seeing of the integration of oral health in primary health care in Indigenous populations: a scoping review. Int J Equity Health. 2020 Dec;19(1):1-8.

20. Mamerto ML, Calache H, Ivanovic A, Bettega A, Martin R, McKee S. Collaborative Oral Health Care. Int J Integr Care. 2021 Feb $26 ; 20(3)$.

21. Tynan A, Deeth L, McKenzie D, Bourke C, Stenhouse S, Pitt J, Linneman H. Integrated approach to oral health in aged care facilities using oral health practitioners and teledentistry in rural Queensland. Aust J Rural Health. 2018 Aug;26(4):290-4.

22. Britt H, Miller GC, Henderson J, Bayram C, Harrison C, Valenti L, Pan Y, Charles J, Pollack AJ, Wong C, Gordon J. General practice activity in Australia 2015-16. Sydney University Press; 2016 Sep 1.

23. Classification Committee of the World Organization of Family Doctors. ICPC-2: International classification of primary care. 2nd edn. Oxford: Oxford University Press; 1998.

24. WHO Collaborating Centre for Drug Statistics Methodology. Anatomical Therapeutic Chemical (ATC) classification index with defined daily doses (DDDs). Oslo (NO): Norwegian Institute of Public Health; 2016.

25. Australian Bureau of Statistics. 2033.0.55.001 - Census of Population and Housing: Socio-Economic Indexes for Areas (SEIFA), Australia, 2016 [Internet]. Canberra: Australian Bureau of Statistics, 2018 Mar 27 [cited 2021 Dec 11]. Available from:

Page 13/15 
https://www.abs.gov.au/ausstats/abs@.nsf/Lookup/by\%20Subject/2033.0.55.001\%7E2016\%7EMain\%20Features\%7EIRSAD\%7E20

26. Australian Bureau of Statistics. 1270.0.55.005 - Australian Statistical Geography Standard (ASGS): Volume 5 - Remoteness Structure, July 2016 [Internet]. Canberra: Australian Bureau of Statistics, 2018 Mar 16 [cited 2022 Jan 22]. Available from: https://www.abs.gov.au/AUSSTATS/abs@.nsf/Lookup/1270.0.55.005Main+Features1July\%202016?0penDocument

27. Austin PC, Hux JE. A brief note on overlapping confidence intervals. J Vasc Surg. 2002 Jul 1;36(1):194-5.

28. Allin S, Farmer J, Quiñonez C, Peckham A, Marchildon G, Panteli D, Henschke C, Fattore G, Lamloum D, Holden AC, Rice T. Do health systems cover the mouth? Comparing dental care coverage for older adults in eight jurisdictions. Health Policy. 2020 Jul 2;124(9):998-1007.

29. NHS England. Understanding the new NHS [Internet]. London: BMJ, 2014 Jun 26 [cited 2021 Dec 11]. Available from: https://www.nhs.uk/nhsengland/thenhs/about/documents/simple-nhs-guide.pdf

30. Ministry of Health. Publicly funded dental care [Internet]. Wellington (NZ): Ministry of Health, 2019 [updated 2019 Jun 25 ; cited 2021 Dec 11]. Available from: https://www.health.govt.nz/your-health/services-and-support/health-care-services/visiting-dentist/publiclyfunded-dental-care

31. Canadian Dental Association. The State of Oral Health in Canada [Internet]. Ottawa (Canada): Canadian Dental Association, 2017 Mar [cited 2021 Dec 11]. Available from: https://www.cda-adc.ca/stateoforalhealth/servicescanada/

32. Hadler-Olsen E, Jönsson B. Oral health and use of dental services in different stages of adulthood in Norway: a cross sectional study. BMC Oral Health. 2021 Dec;21(1):1-7.

33. Chrisopoulos S, Luzzi L, Ellershaw A. Dental Care. In: ARCPOH, editors. Australia's Oral Health: National Study of Adult Oral Health 2017-18. Adelaide (AU): The University of Adelaide; 2019. p. 97-124.

34. Australian Institute of Health and Welfare. Frequent GP attenders and their use of health services in 2012-13. Canberra: AlHW; 2015.

35. Vargas CM, Macek MD, Marcus SE. Sociodemographic correlates of tooth pain among adults: United States, 1989. Pain. 2000 Mar 1;85(1-2):87-92.

36. Levin KA, Davies CA, Topping GV, Assaf AV, Pitts NB. Inequalities in dental caries of 5-year-old children in Scotland, 1993-2003. Eur J Public Health. 2009 Jun 1;19(3):337-42.

37. Do L, Luzzi L. Oral health status. In: ARCPOH, editors. Australia's Oral Health: National Study of Adult Oral Health 2017-18. Adelaide (AU): The University of Adelaide; 2019. p. 38-96.

38. Marmot M, Bell R. Social determinants and dental health. Adv Dent Res. 2011 May;23(2):201-6.

39. Riggs E, Gibbs L, Kilpatrick N, Gussy M, van Gemert C, Ali S, Waters E. Breaking down the barriers: a qualitative study to understand child oral health in refugee and migrant communities in Australia. Ethn Health. 2015 May 4;20(3):241-57.

40. Valdez R, Spinler K, Kofahl C, Seedorf U, Heydecke G, Reissmann DR, Lieske B, Dingoyan D, Aarabi G. Oral Health Literacy in Migrant and Ethnic Minority Populations: A Systematic Review. J Immigr Minor Health. 2021 Aug 27:1-20.

41. Kilpatrick NM, Neumann A, Lucas N, Chapman J, Nicholson JM. Oral health inequalities in a national sample of Australian children aged 2-3 and 6-7 years. Aust Dent J. 2012 Mar;57(1):38-44.

42. Australian Institute of Health and Welfare. Aboriginal and Torres Strait Islander Health Performance Framework 2020 summary report. Canberra (AU): Australian Institute of Health and Welfare; 2020.

43. Jamieson LM, Elani HW, Mejia GC, Ju X, Kawachi I, Harper S, Thomson WM, Kaufman JS. Inequalities in indigenous oral health: findings from Australia, New Zealand, and Canada. J Dent Res. 2016 Nov;95(12):1375-80.

44. AHMAC (Australian Health Ministers Advisory Council). Aboriginal and Torres Strait Islander Health Performance Framework 2017 Report. Canberra (AU): AHMAC; 2017.

45. Durie M. Understanding health and illness: research at the interface between science and indigenous knowledge. Int J Epidemiol. 2004 Oct 1;33(5):1138-43.

46. Mejia GC, Parker EJ, Jamieson LM. An introduction to oral health inequalities among Indigenous and non-Indigenous populations. Int Dent J. 2010 Jun;60(3S2):212-5.

47. Productivity Commission. Report on Government Services 2019 [Internet]. Melbourne (AU): Productivity Commission; 2019. Chapter 10, Primary and Community Health. [cited 2021 Dec 11]. Available from: https://www.pc.gov.au/research/ongoing/report-ongovernment-services/2019/health/primary-and-community-health/rogs-2019-parte-chapter10.pdf

48. Department of Health. Dentists - Health Workforce Data [Internet]. Canberra (AU): Department of Health, 2019 [cited 2021 Dec 11]. Available from: https://hwd.health.gov.au/resources/publications/factsheet-alld-dentists-2017.pdf 
49. Australian Institute of Health and Welfare. Australia's health 2014 [Internet]. Canberra (AU): AlHW; 2014. Chapter 5.6, Health in regional and remote areas. [cited 2021 Dec 11]. Available from: https://www.aihw.gov.au/getmedia/c131e007-43e0-44fd-90823cf15648d8bb/5_6-health-regional-remote-a.pdf.aspx

50. Cope AL, Wood F, Francis NA, Chestnutt IG. General practitioners' attitudes towards the management of dental conditions and use of antibiotics in these consultations: a qualitative study. BMJ Open. 2015 Oct 1;5(10):e008551.

51. Timmerman A, Parashos P. Management of dental pain in primary care. Aust Prescr. 2020 Apr;43(2):39.

52. Colla CH, Mainor AJ, Hargreaves C, Sequist T, Morden N. Interventions aimed at reducing use of low-value health services: a systematic review. Med Care Res Rev. 2017 Oct;74(5):507-50.

53. Abbott B, Zybutz C, Scott KM, Eberhard J, Widmer R. A review of the hours dedicated to oral health education in medical programmes across Australia. Intern Med J. 2018 Sep;48(9):1035-40.

54. Ahmad MS, Abuzar MA, Razak IA, Rahman SA, Borromeo GL. Educating medical students in oral health care: current curriculum and future needs of institutions in Malaysia and Australia. Eur J Dent Educ. 2017 Nov;21(4):e29-38.

55. Ferullo A, Silk H, Savageau JA. Teaching oral health in US medical schools: results of a national survey. Acad Med. 2011 Feb 1;86(2):226- 30.

56. Barnett T, Hoang H, Stuart J, Crocombe L. "Sorry, I'm not a dentist": perspectives of rural GPs on oral health in the bush. Med J Aust. 2016 Jan;204(1).

57. Australian Institute of Health and Welfare. Oral health and dental care in Australia [Internet]. Canberra: Australian Institute of Health and Welfare, 2021 [cited 2022 Jan. 26]. Available from: https://www.aihw.gov.au/reports/dental-oral-health/oral-health-and-dentalcare-in-australia

58. Thomson WM, Williams SM, Broadbent JM, Poulton R, Locker D. Long-term dental visiting patterns and adult oral health. Journal of dental research. 2010 Mar;89(3):307-11.

\section{Figures}

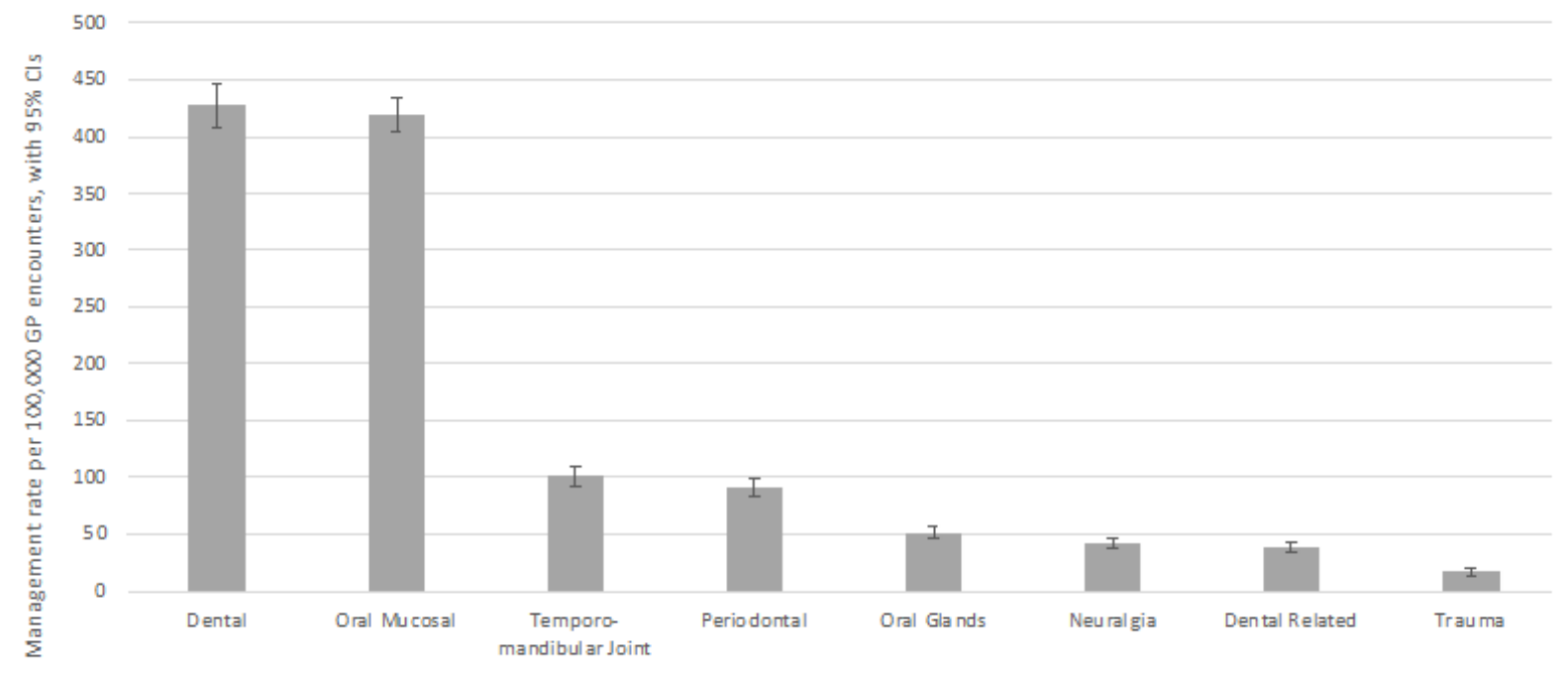

Figure 1

Management rate of oral conditions per 100,000 GP encounters by definition of oral problem from 2006 to 2016.

\section{Supplementary Files}

This is a list of supplementary files associated with this preprint. Click to download.

- Supplementary.docx 